\title{
Erysipelothrix rhusiopathiae. I. Isolation and characterization from pinnipeds and bite/abrasion wounds in humans
}

\author{
Lynn D. Suer, Neylan A. Vedros \\ Dept of Biomedical and Environmental Health Sci., School of Public Health, University of California, Berkeley, California \\ 94720 , USA
}

\begin{abstract}
The bacterium Erysipelothrix rhusiopathiae was isolated from the teeth/gum margin area of 2 of 10 2-yr-old northern fur seals Callorhinus ursinus (NFS), 2 of 20 northern elephant seals Mirounga angustirostris (ES), a random sample of Atlantic herring fish meal, and 12 of 116 bite wounds in marine mammal handlers. The isolates were typical of E. rhusiopathiae and represented Serotypes 2 , $5,6,7,8,9,16,21$, and a possible new serotype. Two isolates from NFS had partial reaction with Serotype 2 . Selected serotypes were virulent for mice $\left(\mathrm{LD}_{50}=1 \times 10^{1.7}\right.$ bacteria). Mice challenged with Serotypes 4 and 5 were passively protected by commercial horse antiserum to E. rhusiopathiae. The marine mammal isolates were most sensitive to penicillin followed by tetracycline then streptomycin.
\end{abstract}

\section{INTRODUCTION}

Erysipelothrix rhusiopathiae is the etiologic agent of erysipelas, a serious bacterial disease of fowl, rodents, a variety of wild and domestic animals and occasionally humans (Wood 1970). The clinical manifestations vary from the classical rhomboid urticaria ('diamond skin') lesions which are pathognomonic for swine, to septicemia, polyarthritis, pneumonia, and death (Wood 1981, Smith 1983).

Cetaceans are the most susceptible of marine mammals to erysipelas and the disease has been reported in Tursiops truncatus, Tursiops aduncus, Stenella plagiodon, Grampus griseus, and Lagenorhynchus obliquidens (Siebold \& Neil 1956, Simpson et al. 1958, Geraci et al. 1966, Thurman et al. 1983). There are only scattered reports of erysipelas infection in pinnipeds. Svenkerud et al. (1951) described cutaneous lesions in hooded seals, harp seals, and ringed seals which resembled swine erysipelas and were manifested by hemorrhagic infiltration of various sizes in the subcutaneous blubber. The authors were unable to observe the extent or development of the infection or conduct any biochemical studies on the etiologic agent. They temporarily assigned the name Corynebacterium phocae to the isolate. Benkovsky \& Golovina (1971) examined two 5- to 6-mo-old seal pups and found the internal organs of both 'infested' with E. rhusiopathiae.

There are no reports, to the authors' knowledge, of the isolation of Erysipelothrix rhusiopathiae from healthy pinnipeds or from pinniped bite wounds in humans. This report describes the isolation and characterization of E. rhusiopathiae from a variety of pinnipeds and bite wounds and abrasions of animal handlers working with pinnepeds.

\section{MATERIAL AND METHODS}

Isolation of microorganisms. Isolates of Erysipelothrix rhusiopathiae were obtained as follows:

St Paul, Pribilof Islands, Alaska. Dacron swabs of the tooth/gum margin of twelve 2- to 3-yr-old male northern for seals Callorhinus ursinus (NFS) were placed in Stuart's Transport Medium (Gibco Labs., Grand Island, NY, USA), held at $4^{\circ} \mathrm{C}$ for 1 to $2 \mathrm{wk}$, plated on Modified Blood Agar containing $0.04 \%$ sodium azide (MBA; Harrington \& Hulse 1971), and processed as described below

California Marine Mammal Center, California (CMMC). (a) Dacron swabs of the toothigum margin of 6 harbor seals Phoca vitulina richardsi (HS), 20 north- 
ern elephant seals Mirounga angustirostus (ES), and 2 California sea lions Zalophus californianus (CSL) were placed in Wood's liquid medium (Wood 1965), held at $4^{\circ} \mathrm{C}$ for 1 to $16 \mathrm{wk}$, and processed as described below.

(b) Dacron swab cultures were taken from bite and abrasion wounds of 116 animal technicians working with the above 3 pinniped species. The cultures were taken by expressing blood and fluid from the wound soon after the trauma and before medication or first aid was administered. The swabs were placed in precooled Wood's liquid medium, held at $4{ }^{\circ} \mathrm{C}$ for 1 to 16 wk, and processed as described below.

Incubation. The MBA plates from NFS were incubated at $35^{\circ} \mathrm{C}$ for $48 \mathrm{~h}$ (air). The samples from the CMMC in Wood's liquid medium were incubated at $35^{\circ} \mathrm{C}$ for $7 \mathrm{~d}$. During this period aliquots were plated on MBA on Days 3 and 7 and incubated at $35^{\circ} \mathrm{C}$ for $48 \mathrm{~h}$. All MBA plates were examined after incubation and small translucent, smooth colonies (whether greening of the blood agar or not) were cloned to Kligler or Triple sugar-iron (TSI, Difco Co., Detroit, MI, USA) as described by Vicker \& Bieri (1958). Those cultures which produced $\mathrm{H}_{2} \mathrm{~S}$ with slow acidification of the butt and slant without gas were cloned to MBA (containing no sodium azide) for staining, purity and further biochemical tests.

Biochemical tests. Gram stain, oxidase and catalse tests were determined on 18 to 24 h cultures. Andrade's $1 \%$ carbohydrate broth (White \& Shuman 1961) was inoculated and included the following sugars: arabinose, dextrin, dulcitol, fructose, galactose, glucose, glycerol, inositol, inulin, lactose, maltose, mannitol, mannose, raffinose, rhamnose, salicin, sorbitol, sucrose, trehalose, and xylose (Wood 1970). Esculin was included to rule out Bacillus species and nitrate and urea tests were made to rule out other contaminants. Sterile horse serum (Gibco Labs., Fairlawn, NJ, USA) were added (2 to 3 drops) to each biochemical test prior to incubation. All tests for sugar utilization were determined after 24 $\mathrm{h}$ incubation, esculin and urea after $10 \mathrm{~d}$, and nitrate reduction after $7 \mathrm{~d}$.

Serology. All presumptive isolates of Erysipelothrix rhusiopathiae were lyophilized in Trypticase Soy Broth (TSB ${ }_{i}$ Difco Co.) containing 6 " lactose. Confirmation of identity and serotyping by agar diffusion were done through the courtesy of Dr Richard L. Wood, National Animal Diseases Center, Ames, IA, USA

Mouse virulence. Log-phase cultures (nutrient broth, $5 \%$ horse serum) of Serotypes 4 and 5 from NFS were used to determine the $\mathrm{LD}_{\text {so }}$ in mice. Groups of 10 mice (Namru strain, 16 to $20 \mathrm{~g}$ ) were injected intraperitoneally (i. p.) with $0.1 \mathrm{ml}$ of various dilutions of the culture. A control group received $0.1 \mathrm{ml}$ i.p. of the broth. Death was recorded over $6 \mathrm{~d}$ and the $\mathrm{LD}_{50}$ determined by the method of Reed \& Muench (1938).
Passive protection of mice was determined as described by Wood (1970). Groups of 10 mice were injected intramuscularly (i.m.) in one flank with $0.1 \mathrm{ml}$ of culture and immediately thereafter the other flank was injected i.m. with $0.3 \mathrm{ml}$ of standard equine Erysipelothrix rhusiopathiae antiserum (serial no. 100-897, Bioceutic Labs. Inc., St Joseph, MO, USA). The mice were observed for $6 \mathrm{~d}$.

Antibiotic sensitivity. Stock solutions of potassium penicillin G, streptomycin sulfate, and tetracycline hydrochloride (Sigma Co.) were prepared as described by Bailey \& Scott (1974). The minimum inhibitory concentration (MIC) and minimum lethal concentration (MLC) were determined as described by Lennette et al. (1974) using cultures grown in Mueller Hinton Broth (Difco Co.) containing $1 \%$ horse serum.

\section{RESULTS}

\section{Isolations}

As noted in Table 1, of the 40 pinnipeds and 116 bite/ abrasion wounds sampled, 17 isolates of Erysipelothrix rhusiopathiae were recovered. Two of these isolates were from NFS, 2 from ES, 1 from Atlantic herring fish meal, and 12 from bite/abrasion wounds. The 12 wounds were inflicted by $1 \mathrm{CSL}, 1 \mathrm{HS}$ and $10 \mathrm{ES}$.

Table 1. Frequency of isolation of Erysipelothrix rhusiopathiae

\begin{tabular}{lc}
\hline Source & No. positive/No. sampled \\
\hline Northern fur seal & $2 / 12$ \\
California sea lion & $0 / 2$ \\
Farbor seal & $0 / 6$ \\
Northern elephant seal & $2 / 20$ \\
Herring fish meal & $2 / 1$ \\
Herring (whole fish) & $0 / 2$ \\
Bite/abrasion wounds & $12 / 116$
\end{tabular}

\section{Biochemical reactions}

All 17 isolates were negative for acid production with arabinose, dulcitol, glycerol, inositol, inulin, mannitol, raffinose, rhamnose, sorbitol, salicin, and xylose; and positive for dextrin, fructose, galactose, glucose, lactose, and maltose. All isolates produced $\mathrm{H}_{2} \mathrm{~S}$ in TSI and were negative for esculin and in the urea and nitrate reduction test. Some variations in reactions with several sugar substrates were noted with several isolates from the bite wounds. These variations are shown in Table 2 
Table 2. Variability in acid production of mannose, sucrose, and trehalose by Erysipelothrix rhusiopathiae isolates. +: Acid produced $_{i}-:$ acid not produced ${ }_{i} \pm$ : slight acid produced

\begin{tabular}{|c|c|c|c|}
\hline Isolate \# & Mannose & $\begin{array}{l}\text { Sugars } \\
\text { Sucrose }\end{array}$ & Trehalose \\
\hline ATCC $19414^{d}$ & \pm & - & - \\
\hline 1 & - & + & - \\
\hline 6 & + & - & - \\
\hline 7 & + & - & - \\
\hline 8 & - & - & - \\
\hline 9 & - & - & - \\
\hline 12 & - & - & - \\
\hline 13 & + & $+b$ & - \\
\hline 14 & - & - & + \\
\hline 17 & $t^{b}$ & + & - \\
\hline 29 & + & $+b$ & - \\
\hline 31 & + & $+b$ & - \\
\hline 32 & + & - & - \\
\hline 47 & + & - & - \\
\hline 60 & \pm & - & - \\
\hline 80 & $+t^{b}$ & - & - \\
\hline
\end{tabular}

\section{Serotypes}

The serotypes of all 17 isolates are shown in Table 3. As noted, the isolates from the NFS reacted only partially with Serotype 2 antisera and with none of the other 21 serotypes (R. Wood pers. comm.). Serotypes 2 . 5 , and 9 were however the predominant serotypes. It was of interest that Isolate \#31 from patient P.S. who was bitten by ES No. 177 was Serotype 9. However when the teeth/gum margin of this same animal was cultured the same day (Isolate \#32) the serotype recovered was Type 21 . The lyophilized vials of Isolate \# 9 were lost and attempts were made to reisolate it 1 yr later from the original holding medium which had been held at $4^{\circ} \mathrm{C}$. The newly recovered isolate (\#9A) proved to Serotype 7 rather than Serotype 5.

\section{Mouse virulence}

The $L D_{50}$ in mice for Serotypes 4 and 5 was $1 \times 10^{1.7}$ bacteria. The commercial Erysipelothrix rhusiopathiae antiserum protected $100 \%$ of the mice when challenged with $6.7 \times 10^{6}$ (Serotype 4 ) and $5.7 \times 10^{6}$ (Serotype 5) microorganisms.

\section{Antibiotic sensitivity}

The antibiotic sensitivities (MIC and MIC) of 5 selected serotypes of Erysipelothrix rhusiopathiae are shown in Table 4. The MIC of penicillin and tetra-
Table 3. Erysipelothrix rhusiopathiae. Serotypes isolated from pinnipeds and bite/abrasion wounds of humans by pinnipeds

\begin{tabular}{|c|c|c|}
\hline Isolate \# & Source & Serotype \\
\hline 1 & Herring fish meal & 8 \\
\hline 4 & NFS $^{a}$ & 2 (partial) \\
\hline 5 & NFS & 2 (partial) \\
\hline 6 & ES No. 170 & 9 \\
\hline 32 & ES No. 177 & 21 \\
\hline \multicolumn{3}{|c|}{ Humans } \\
\hline 7 & ES No. $173(\mathrm{D} . \mathrm{M} .)^{b}$ & 9 \\
\hline 8 & ES No. 190 (B. B.) & 5 \\
\hline 9 & ES No. 190 (R. W.) & 5 \\
\hline $9 A^{c}$ & ES No. 190 (R. W.) & 7 \\
\hline 12 & ES No. 195 (N. S.) & 2 \\
\hline 13 & ES No. 178 (R. W.) & 2 \\
\hline 14 & ES No. 186 (J. O.) & 5 \\
\hline 17 & ES No. 180 (S. O.) & 16 \\
\hline 29 & ES No. 205 (D. V.) & 5 \\
\hline 31 & ES No. 177 (P. S.) & 9 \\
\hline 47 & HS No. 154 (H. S.) & 9 \\
\hline 60 & ES No. 266 (C. G.) & 6 \\
\hline 80 & CSL 'Dale' (L. C.) & 2 \\
\hline \multicolumn{3}{|c|}{$\begin{array}{l}\text { "NFS: northern fur seal; ES: northern elephant seal; HS: } \\
\text { harbor seal; CSL: California sea lion } \\
\text { " Patient's initials } \\
\text { " Repeat culture } 1 \text { yr after storage at } 4{ }^{\circ} \mathrm{C} \text { of original } \\
\text { holding medium from which Isolate \#9 was isolated }\end{array}$} \\
\hline
\end{tabular}

cycline were similar $\left(0.5 \mu \mathrm{g} \mathrm{ml}^{-1}\right)$ and 32 -fold more effective than streptomycin. Penicillin was however the most effective in the MLC test $\left(0.5 \mu \mathrm{g} \mathrm{ml}^{-1}\right.$ vs $64 \mu \mathrm{g} \mathrm{ml}{ }^{-1}$ for streptomycin and tetracycline). In the MLC test it was estimated that at least $99 \%$ of the bacteria were killed at the minimum antibiotic concentrations noted above.

\section{DISCUSSION}

The method of isolation of Erysipelothrix rhusiopathiae used in this study proved practical and reproducible. We observed that the initial holding of the cultures at $4^{\circ} \mathrm{C}$ before attempting isolation on MBA may be beneficial to successfully obtaining isolates. We have no experimental data to support this view but until we followed this procedure we were unsuccessful in obtaining isolates during many attempts. Since the specimens for culture were not obtained from clinical cases of erysipelas but rather from animals with mixed, normal flora, the lower temperature perhaps prevented overgrowth of other bacteria in the very rich holding and plating media.

The serotypes of the 17 isolates represented known serotypes from terrestrial animals. Two isolates (\# 4 and 5) from NFS may represent new serotypes. These 
Table 4. Erysipelothrix rhusiopathiae. Antibiotic sensitivities of 5 selected serotypes isolated from pinnipeds and bite/abrasion wounds of humans by pinnipects. MIC: minimum inhibitory concentration; MLC: minimum lethal concentration (> $99 \%$ killed)

\begin{tabular}{|c|c|c|c|c|}
\hline Isolate \# & Serotype & $\begin{array}{l}\text { Penicillin } \\
\left(\mu \mathrm{g} \mathrm{ml} \mathrm{l}^{-1}\right)\end{array}$ & $\begin{array}{l}\text { MIC/MLC } \\
\text { Tetracycline } \\
\text { (ug ml } \mathrm{ml}^{-1} \text { ) }\end{array}$ & $\begin{array}{l}\text { Streptomycin } \\
\left.\text { (ug } \mathrm{ml}^{-b}\right)\end{array}$ \\
\hline 5 & 2 & $0.5 / 0.5$ & $0.5 / 64$ & $16 / 64$ \\
\hline 7 & 9 & $0.5 / 0.5$ & $0.5 / 64$ & $16 / 64$ \\
\hline 12 & 2 & $0.5 / 0.5$ & $0.5 / 64$ & $16 / 64$ \\
\hline 14 & 5 & $0.5 / 0.5$ & $0.5 / 64$ & $8 / 64$ \\
\hline 17 & 16 & $0.5 / 0.5$ & $0.5 / 64$ & $8 / 64$ \\
\hline 32 & 21 & $0.5 / 0.5$ & $0.5 / 64$ & $16 / 64$ \\
\hline
\end{tabular}

isolates reacted only partially with known Serotype 2 aniserum bui completely with its homologous antiserum (data not shown) and not with any of the other 21 known serotypes. The commercial horse antisera to Erysipelothrix rhusiopathiae (serotypes unknown) did protect against mouse lethality of Serotypes 4 and 5 . The presence of mixed serotypes in pinnipeds stranded and brought to the California Marine Mammal Center was evident by the one instance in which Serotype 21 was isolated from ES No. 177 (Isolate \# 32; Table 3) whereas Serotype 9 was isolated from patient P.S. bitten by the same animal on the same day. It is speculated that a similar mixed culture was present in the culture in which Serotype 5 was first isolated (Isolate \#9; Table 3) and Serotype 7 recovered 1 yr later from the same holding medium.

It is generally believed that marine mammals acquire Erysipelothrix rhusiopathiae from the fish in their diet. There are numerous reports of the presence of this microorganism in fish which show no sign of illness. Fish have been experimentally infected with $E$. rhusiopathiae and the microorganism recovered from many tissues and the urine (Smith 1983). The pinnipeds in this study brought to the California Marine Mammal Center had a variety of clinical manifestations. Some of the animals required tube feeding of fish meal whereas others could eat whole fish the first day in captivity. We sampled only one large lot of blended, frozen then thawed Atlantic herring and readily isolated $E$. rhusiopathiae (Isolate \#1). Samples of whole fish from the same lot and on the same day were both negative for isolation of E. rhusiopathiae. Further sampling of random lots of fish with serotyping is needed to determine the extent of exposure of the animals to $E$ rhusiopathiae and the public health implication for the animal technicians. Isolates were however obtained from young, adult male NFS when they returned to the rookery after a 2 yr pelagic cycle. Our further studies (to be published) confirm that wild pinnipeds and cetaceans are exposed to E. rhusiopathiae in their natural environment.
Acknowledgements. We thank Dr Richard L. Woods, National Animal Diseases Center, Ames, Iowa, USA for his generous help in confirming and serotyping our isolates, and the Staff of the California Marine Mammal Center for their support and continuous help.

\section{LITERATURE CITED}

Bailey, W R., Scott, E. G. (1974). Diagnostic microbiology: a textbook for the isolation and identification of pathogenic microorganisms, 4th edn. C. V Mosby Co., St Louis, $p$. $314-318$

Benkovsky, L. M., Golovina, T. I. (1971). Infestation of $B$. perfringens pyocyaneum Schroeter (sic) and Erysipelothrix rhusiopathiae in fur seals. Inst. morsk. ryb. Khoz. Oceanogr. 82: 124-127

Geraci, J. R., Sauer, R. M., Medway, W. (1966). Erysipelas in dolphins. Am. J. Vet. Res. 27: 597-606

Harrington, R., Hulse, D. C. (1971). Comparison of two plating media for the isolation of Erysipelothrix rhusiopathiae from enrichment broth culture. Appl. Microbiol. 22: 141-142

Lennette, E. H., Spaulding, E. H., Truant, J. P. (1974). Manual of clinical microbiology, 2nd edn. An. Soc. Microbiology, Washington, D. C., p. 410-415, 431-432

Reed, L. J., Muench, H. (1938). A simple method of estimating fifty percent endpoints. Am. J. Hygiene 27 493-497

Siebold, H. R., Neal, J. E. (1965) Erysipelothrix septicemia in the porpoise. J. Am. vet. med. Ass. 128: 537-539

Simpson, C. F., Wood, F. G., Young, F. (1958). Cutaneous lesions on a porpoise with erysipelas. J. Am vet. med. Ass. 132: $558-560$

Smith, G. (1983). Erysipelothrix and Listeria. In: Parker, M. T (ed.) Topley and Wilson's principles of bacteriology, 7th edn. Williams and Wilkins Co., Baltimore, p. 50-59

Svenkerud, R. R., Rosted, A. F., Thorshaug, K. (1951). A Iesion in seals reminding greatly of swine erysipelas. Nord. Veterinaermed. 3: 147-169

Thurman, G. D., Downes, S. J. T., Fothergill, M. B., Goodwin, N. M., Hegarty, M. M. (11983). Diagnosis and successful treatment of subacute erysipelas in a captive dolphin. J. S. Afr vet. Ass. 54: 193-200

Vicker, C. L., Bierer, B. W. (1952). Triple sugar iron agar as an aid in the diagnosis of erysipelas. J. Am vet. med. Ass. 133: $453-458$

White, T G., Shuman, R. d. (1961). Fermentation reactions of Erysipelothix rhusiopathiae. J. Bacteriol. 82: 595-599

Wood, R. L. (1965). A selective liquid medium utilizing antibiotics for isolation of Erysipelothrix insidiosa. Am. J. vet. Res. 26: 1303-1308 
Wood, R. L. (1970). Erysipelothrix. In: Blair, J. E., Lennette, E H., Truant, J. P. (eds.) Manual of clinical microbiology. Am. Soc. for Microbiol., Bethesda, p. 101-105
Wood, R. L. (1981). Erysipelas. In: Leman, A. D., Glock, R. D. Mengeling, W. L., Penny, R. H. C., Scholl, E., Straw, B. (eds.) Diseases of swine. Iowa State Univ. Press, Ames, p. 457-470

Responsible Subject Editor Professor M. D. Dailey; accepted for printing on June 14, 1988 